\title{
Factors associated with dyslipidemia and its prevalence among Awash wine factory employees, Addis Ababa, Ethiopia: a cross-sectional study
}

\author{
Daniel Angassa ${ }^{1 *}$, Samrawit Solomon ${ }^{2}$ and Awol Seid ${ }^{2}$
}

\begin{abstract}
Background: Dyslipidemia is a highly prevalent and modifiable risk factor for atherosclerotic cardiovascular diseases. Though the problem is significant in Ethiopia, available data in this regard is very poor among alcoholic beverage industrial workers. This study aimed to assess factors associated with dyslipidemia and its prevalence among Awash wine factory employees in Addis Ababa, Ethiopia.
\end{abstract}

Methods: A cross-sectional study was conducted among 335 randomly selected employees of Awash wine factory, Addis Ababa, Ethiopia from January to February 2021. Data was collected by a face-to-face interview technique using the WHO STEPwise approach. Data were entered and analyzed using Epi Info 7 and SPSS version 26, respectively. Both bivariable and multivariable logistic regression analyses were performed to identify factors associated with dyslipidemia. All statistical tests were declared significant at $p$-value $<0.05$.

Results: The overall prevalence of dyslipidemia was $67.8 \%$ (95\% Cl 62.5-72.7\%). Elevated total cholesterol, elevated triglycerides, reduced high-density lipoprotein, and elevated low-density lipoprotein was found in $25.4 \%, 33.4 \%$, $50.7 \%$, and $21.5 \%$ of participants, respectively. Dyslipidemia was significantly associated with age group 30-39 years $(A O R=2.51 ; 95 \% \mathrm{Cl} 1.16-5.44, p=0.019), \geq 40$ years $(A O R=6.45 ; 95 \% \mathrm{Cl} 2.01-20.71, p=0.002)$, current alcohol consumption ( $A O R=3.37 ; 95 \% \mathrm{Cl} 1.70-6.66, p<0.001$ ), eating vegetables $<2$ days per week ( $\mathrm{AOR}=2.89 ; 95 \% \mathrm{Cl} 1.54-5.43$, $p=0.001)$, sitting duration of $>4 \mathrm{~h}$ per day $(\mathrm{AOR}=1.96 ; 95 \% \mathrm{Cl} 1.03-3.74, p=0.041)$, and raised waist circumference ( $\mathrm{AOR}=4.56 ; 95 \% \mathrm{Cl} 2.07-10.08, p<0.001$ ).

Conclusions: High prevalence of dyslipidemia was found among Awash wine factory employees in Addis Ababa. Periodic screening of high-risk groups along with effective health promotion and education which encourages a healthy lifestyle is essential.

Keywords: Dyslipidemias, Prevalence, Risk factors, Wine factory, Ethiopia

*Correspondence: danielssa25@gmail.com

${ }^{1}$ Lideta Sub-City Health Office, Addis Ababa, Ethiopia

Full list of author information is available at the end of the article

\section{Background}

Globally, cardiovascular diseases (CVD) are the leading cause of mortality with high incidence and prevalence in countries of all economic groups. In 2016, CVD were responsible for 17.9 million deaths worldwide, accounting for $31 \%$ of all global deaths [1-3]. In recent decades, most African countries including Ethiopia have

(c) The Author(s) 2022. Open Access This article is licensed under a Creative Commons Attribution 4.0 International License, which permits use, sharing, adaptation, distribution and reproduction in any medium or format, as long as you give appropriate credit to the original author(s) and the source, provide a link to the Creative Commons licence, and indicate if changes were made. The images or other third party material in this article are included in the article's Creative Commons licence, unless indicated otherwise in a credit line to the material. If material is not included in the article's Creative Commons licence and your intended use is not permitted by statutory regulation or exceeds the permitted use, you will need to obtain permission directly from the copyright holder. To view a copy of this licence, visit http://creativecommons.org/licenses/by/4.0/. The Creative Commons Public Domain Dedication waiver (http://creativeco mmons.org/publicdomain/zero/1.0/) applies to the data made available in this article, unless otherwise stated in a credit line to the data. 
been undergoing an epidemiological transition which manifested by the emergence of cardiovascular diseases. Among the modifiable CVD risk factors, dyslipidemia is the commonest risk factor globally and even in Africa. At least one in five adults in the general population of Africa has dyslipidemia $[4,5]$.

Dyslipidemia is a condition that occurs because of abnormalities in the plasma lipids such as elevated plasma total cholesterol (TC), elevated low-density lipoprotein cholesterol (LDL-C), elevated triglycerides (TG), and reduced high-density lipoprotein cholesterol (HDL-C) levels, occurring singly or in combinations [6]. It is a highly prevalent and modifiable risk factor for atherosclerotic cardiovascular diseases (CVD) such as coronary heart diseases (CHD) resulting in serious morbidity, mortality, and medical costs worldwide [7].

In 2016, the Global Burden of Disease study reported that high concentrations of total cholesterol caused about 4.4 million deaths and 93.8 million disabilityadjusted life-years (DALYs) [8]. In Africa, a metaanalysis conducted in 2018 showed an overall 29.7\% prevalence of dyslipidemia with a higher prevalence in urban areas. In sub-Saharan Africa, a high prevalence of more than $35 \%$ is reported in some areas [5]. A national survey conducted in Ethiopia in 2015 showed a $68 \%$ and $21 \%$ prevalence of low HDL-cholesterol and hypertriglyceridemia, respectively [9]. Previous observational studies indicated that excessive alcohol intake largely contributes to the development of dyslipidemia mainly hypertriglyceridemia. A dose-response relationship has been also described between alcohol intake and blood lipids, especially with HDL-C, LDL-C, and triglyceride (TG) levels [10-12].

Furthermore, recent studies showed that using PCSK9 inhibitors had a multimodal benefit in improving the quality of life in patients at high cardiovascular risk. Besides providing a good clinical prognostic improvement mainly reducing LDL-C levels substantially, it had also an economic advantage due to its costeffectiveness [13]. The additional benefit of the use of PCSK9 inhibitors in high cardiovascular risk patients is significantly higher adherence and low discontinuation rate than other lipid-lowering drugs [14].

Even if, various risk factors of dyslipidemia have been identified through numerous studies, most of the studies focused on participants with co-morbidities such as diabetes mellitus, hypertension, and HIV/ AIDS [15-17]. And despite its association with heavy alcohol consumption $[10,11]$, available data regarding the prevalence of dyslipidemia in alcoholic beverage industrial workplaces in Ethiopia is very poor. Therefore, this study aimed to assess factors associated with dyslipidemia and its prevalence among Awash wine factory employees in Addis Ababa, Ethiopia.

\section{Methods}

\section{Study design and setting}

An institution-based cross-sectional study design was conducted from January to February 2021 in Awash Wine factory which was selected purposively based on the availability of recent laboratory data of its employees. Awash wine factory is one of the many alcoholic beverage factories in Ethiopia which produces wine. It is the oldest wine factory in the country, established in 1943. It has three sites in Addis Ababa with a total of 653 permanent employees. All permanent employees 18 years of age and above and who have been working at the wine factory for at least one year were included in this study. Whereas, pregnant women, employees with a medical report older than November 2020, and incomplete medical files were excluded.

\section{Sample size and sampling technique}

The required sample size was determined by using a single population proportion formula based on a similar study conducted among adult residents of Mekelle city, northern Ethiopia which showed an estimated $66.7 \%$ prevalence of dyslipidemia [18] with the assumption of $95 \%$ level of confidence, $4 \%$ margin of error, and $80 \%$ power. After using a finite population correction formula and considering a $10 \%$ non-response rate, the calculated sample size was 322 .

A simple random sampling technique was used to select the study participants from all three sites of the factory. First, the total number of permanent employees from all three sites in Addis Ababa was identified. Then, after obtaining a list of all permanent employees of each site from the human resource department of the factory, participants were selected using a simple random sampling method after assigning study identification numbers to each employee on the sampling frame to minimize selection bias.

\section{Data collection}

Data was collected by a face-to-face interview technique using a standardized questionnaire adopted from the WHO STEPwise approach for chronic disease risk factors [19] after performing some modifications. First, the modified questionnaire which is in the English language was translated into the local language which is Amharic and translated back to English by another person to check for its consistency. The data collectors were health care professionals (two nurses and one health officer) working in the clinics of the factory. One data collector was selected 
from each site and two days of training on the data collection process was conducted. After obtaining informed consent, data collectors administered the questionnaire using face-to-face interviews and performed physical measurements using standardized instruments. Before the actual data collection started, the adopted questionnaire was pre-tested on 5\% (17) of the sample size among employees of a similar alcohol factory, National Alcohol and Liquor Factory, for its consistency and sensitivity.

Body weight was measured in kilograms without shoes and in light clothes using a calibrated weight scale. Body height was also measured in centimeters without shoes in standing upright position on a flat surface. Body Mass Index (BMI) was calculated as weight in $\mathrm{kg}$ divided by height in meters squared. Waist circumference was measured by using a non-elastic tape around the bare abdomen at the midpoint between the lower margin of the last palpable rib and the top of the iliac crest of the hip bone. Blood pressure was measured using a standard mercury sphygmomanometer on the right arm in a sitting position after participants rested for a minimum of $10 \mathrm{~min}$. Blood pressure was measured twice $10 \mathrm{~min}$ apart and the average reading was recorded.

Fasting blood glucose levels and all the lipid profiles (total cholesterol, triglyceride, LDL, and HDL cholesterols) were obtained from the medical records of the employees of the factory which was conducted in November 2020. These medical records are a result of the annual medical examination of all permanent employees of the factory as part of the plan of the health care department of the factory.

\section{Definitions}

Dyslipidemia is defined based on the National Cholesterol Education Program-Adult Treatment Panel III (NCEP-ATP III) guidelines as a total cholesterol level $\geq 200 \mathrm{mg} / \mathrm{dl}$, triglycerides $\geq 150 \mathrm{mg} / \mathrm{dl}$, LDL cholesterol $\geq 130 \mathrm{mg} / \mathrm{dl}$, and HDL cholesterol $<40 \mathrm{mg} / \mathrm{dl}$ for men and $<50 \mathrm{mg} / \mathrm{dl}$ for women [20]. Abnormal levels of any of the above lipid parameters were considered as dyslipidemia.

International diabetic federation (IDF) defined raised fasting blood glucose as (FBG) level $\geq 100 \mathrm{mg} / \mathrm{dl}$ or previously diagnosed diabetes or receiving treatment for diabetes. Raised blood pressure is defined as systolic blood pressure $(\mathrm{SBP}) \geq 130 \mathrm{mmHg}$ and/or diastolic blood pressure $(\mathrm{DBP}) \geq 85 \mathrm{mmHg}$ or on the treatment of previously diagnosed hypertension. Body mass index (BMI) was used to classify underweight: $\mathrm{BMI}<18.5 \mathrm{~kg} / \mathrm{m}^{2}$, normal: BMI: $18.5-24.9 \mathrm{~kg} / \mathrm{m}^{2}$, overweight: BMI: $\geq 25 \mathrm{~kg} / \mathrm{m}^{2}$, and obese: $\mathrm{BMI} \geq 30 \mathrm{~kg} / \mathrm{m}^{2}$. Abdominal obesity is defined as waist circumference $\geq 94 \mathrm{~cm}$ for men and $\geq 80 \mathrm{~cm}$ for women [21].
Heavy Alcohol Consumption is defined as the average consumption of 5 or more standard alcoholic drinks per day for men $(\approx 50 \mathrm{gm}$ of alcohol) or 4 or more alcoholic drinks (or 40gm alcohol) for women. A standard alcoholic drink is the equivalent of one glass/can/bottle $(330 \mathrm{ml})$ of regular beer (with $3 \%$ ethanol), one glass $(100 \mathrm{ml})$ of wine $(10 \%$ ethanol), or one glass or measure $(40 \mathrm{ml})$ of distilled spirit, each of which adds up to about $10 \mathrm{~g}$ of ethanol per drink.

Regarding physical activity, vigorous-intensity activities are activities that require hard physical effort and cause large increases in breathing or heart rate such as heavy lifting, aerobic, or fast bicycling. Moderate-intensity activities are activities that cause small increases in breathing or heart rate such as carrying light loads, bicycling at a regular pace, or doubles tennis. Walking: this includes walking to travel from place to place, and any other walking that you might do solely for recreation, sport, exercise, or leisure. And Sitting: include time spent in class, at home, while doing course work, and during leisure time [19].

\section{Data processing and analysis}

The collected data were entered into Epi Info version 7 and exported to SPSS version 26 statistical software for analysis. Data cleaning was performed to check for frequencies, missed or error values, and identified errors were corrected after revision of the original completed questionnaire. Descriptive statistics such as frequency, proportion, mean and standard deviation (SD) were used to summarize variables and evaluate the distribution of responses. Both bivariable and multivariable logistic regression analyses were performed to identify factors associated with dyslipidemia. Variables that were significant at $p$-value $<0.05$ in the bivariable analysis were included in the multivariable analysis to control confounding effects. Adjusted odds ratios (AOR) with 95\% confidence intervals $(95 \% \mathrm{CI})$ were used to determine the strength of associations between dyslipidemia and independent variables and the level of statistical significance was declared at $p$-value $<0.05$. The goodness of fit of the model was checked using the Hosmer-Lemeshow test at $p>0.05$.

\section{Results \\ Socio-demographic and anthropometric characteristics of the participants}

A total of 335 participants were included in this study making the response rate $100 \%$. The majority of participants (63.6\%) were male and $36.4 \%$ were female. About one-third (33.1\%) of the participants were aged 40 years and above, while $43.6 \%$ were in the age group of $30-39$ years with the mean age $\pm S D$ of $36.9 \pm 8.9$ years 
(ranging from 21 to 62 years). Regarding their educational level, all participants have attained education from primary to higher education levels and about half (53.1\%) of them have completed college or university level education. More than half $(55.2 \%)$ of the participants were married and about two-third (67.5\%) were working in the plant/factory department. About a quarter (26\%) of the participants have worked in the factory for 5-9 years and about half (51\%) were earning 5000 to 10,000 ETB monthly (Table 1).

Of the total participants, one hundred and fifty-one (45.1\%) had raised waist circumference. More than a quarter $(28.1 \%)$ of the participants were overweight, while 30 (9\%) were obese. Eighty-three (24.8\%) participants had raised blood pressure. However, only 16 (19.3\%) of them were on anti-hypertensive medication and $13 \%$ were not aware of their elevated blood pressure status. Thirty-eight (11.3\%) participants had raised fasting blood glucose levels and less than half of them (44.7\%) were on anti-diabetic medication (Table 1).

\section{Behavioral and lifestyle characteristics of the participants}

Of the total study participants, current tobacco and chat use were reported by $23(6.9 \%)$ and 47 (14\%), respectively. Nearly three-quarters (74.3\%) of the participants consumed alcohol over the past year preceding the time of data collection. Among current alcohol consumers, 23 (9.2\%) were daily consumers, and $70(28.1 \%)$ consumed 2-3 days per week. Two-thirds (65.4\%) of the participants eat vegetables fewer than two days per week, and the majority $(82.1 \%)$ eat fruits fewer than two days per week. Nearly a third (33.1\%) of the participants eat eggs for two days or more per week. Thirty-nine (11.6\%) of the participants were engaged in vigorous-intensity physical activities, while 107 (31.9\%) reported regular walking for $30 \mathrm{~min}$ or more. More than half $(54.6 \%)$ of the participants reported a sitting duration of fewer than four hours per day, and the majority (88.4\%) reported six or more hours of sleeping duration per day (Table 2).

\section{Prevalence of dyslipidemia}

The overall prevalence of dyslipidemia in this study was 67.8\% (95\% CI 62.5-72.7\%). Among individual lipid abnormalities, the highest prevalence was for reduced HDL-C level (50.7\%), followed by elevated triglycerides (33.4\%), elevated total cholesterol (25.4\%), and elevated LDL-C (21.5\%). The mean values of total cholesterol, triglycerides, HDL-C, and LDL-C were $177.5 \pm 42.6 \mathrm{mg} / \mathrm{dl}$, $145.9 \pm 100 \mathrm{mg} / \mathrm{dl}, 43.2 \pm 8.3 \mathrm{mg} / \mathrm{dl}$, and $106.3 \pm 30.7 \mathrm{mg} /$ $\mathrm{dl}$, respectively. The prevalence of reduced HDL-C level
Table 1 Distribution of dyslipidemia by socio-demographic and anthropometric characteristics of employees of Awash wine factory in Addis Ababa, Ethiopia, $2021(n=335)$

\begin{tabular}{|c|c|c|c|}
\hline \multirow[t]{3}{*}{ Variables } & \multirow{3}{*}{$\begin{array}{l}\text { Total } \\
\text { N (\%) }\end{array}$} & \multicolumn{2}{|c|}{ Dyslipidemia } \\
\hline & & Yes & No \\
\hline & & n (\%) & n (\%) \\
\hline \multicolumn{4}{|l|}{ Age (years) } \\
\hline$<30$ & $78(23.3)$ & $30(38.5)$ & $48(61.5)$ \\
\hline 30-39 & $146(43.6)$ & $100(68.5)$ & $46(31.5)$ \\
\hline$>=40$ & $111(33.1)$ & $97(87.4)$ & $14(12.6)$ \\
\hline \multicolumn{4}{|l|}{ Gender } \\
\hline Male & $213(63.6)$ & $140(65.7)$ & $73(34.3)$ \\
\hline Female & $122(36.4)$ & $87(71.3)$ & $35(28.7)$ \\
\hline \multicolumn{4}{|l|}{ Educational level } \\
\hline Primary School & 89 (26.6) & $57(64.0)$ & $32(36.0)$ \\
\hline Secondary School & $68(20.3)$ & 48 (70.6) & $20(29.4)$ \\
\hline College/University & $178(53.1)$ & $122(68.5)$ & $56(31.5)$ \\
\hline \multicolumn{4}{|l|}{ Marital Status } \\
\hline Unmarried $^{\mathrm{a}}$ & $150(44.8)$ & $85(56.7)$ & $65(43.3)$ \\
\hline Married & $185(55.2)$ & $142(76.8)$ & $43(23.2)$ \\
\hline \multicolumn{4}{|l|}{ Working department } \\
\hline Plant (factory) & $226(67.5)$ & $157(69.5)$ & $69(30.5)$ \\
\hline Office & $86(25.7)$ & $54(62.8)$ & $32(37.2)$ \\
\hline Others $^{\mathrm{b}}$ & $23(6.9)$ & $16(69.6)$ & $7(30.4)$ \\
\hline \multicolumn{4}{|l|}{ Total service years } \\
\hline$<5$ & $132(39.4)$ & $70(53.0)$ & $62(47.0)$ \\
\hline $5-9$ & $87(26.0)$ & $58(66.7)$ & $29(33.3)$ \\
\hline$\geq 10$ & $116(34.6)$ & 99 (85.3) & $17(14.7)$ \\
\hline \multicolumn{4}{|l|}{ Monthly income (ETB) } \\
\hline$<5000$ & $76(22.7)$ & $41(53.9)$ & $35(46.1)$ \\
\hline 5000-9999 & $171(51.0)$ & $124(72.5)$ & $47(27.5)$ \\
\hline$\geq 10,000$ & $88(26.3)$ & $62(70.5$ & $26(29.5)$ \\
\hline \multicolumn{4}{|c|}{$\begin{array}{l}\text { Waist circumference }(\mathrm{cm}) \text { (Male) } \\
\text { Female) }\end{array}$} \\
\hline$<94 / 80$ & $180(53.7)$ & $93(51.7)$ & $87(48.3)$ \\
\hline$\geq 94 / 80$ & $155(46.3)$ & $134(86.5)$ & $21(13.5)$ \\
\hline \multicolumn{4}{|c|}{ Body Mass Index $\left(\mathrm{kg} / \mathrm{m}^{2}\right)$} \\
\hline$<18.5$ & $5(1.5)$ & $2(40.0)$ & $3(60.0)$ \\
\hline $18.5-24.9$ & $206(61.5)$ & $118(57.3)$ & $88(42.7)$ \\
\hline $25-29.9$ & $94(28.1)$ & $80(85.1)$ & $14(14.9)$ \\
\hline$\geq 30$ & $30(9.0)$ & $27(90.0)$ & $3(10.0)$ \\
\hline \multicolumn{4}{|l|}{ Blood pressure } \\
\hline Normal $^{c}$ & $252(75.2)$ & $156(61.9)$ & $96(38.1)$ \\
\hline Raised $^{d}$ & $83(24.8)$ & $71(85.5)$ & $12(14.5)$ \\
\hline \multicolumn{4}{|c|}{ Fasting blood glucose $(\mathrm{mg} / \mathrm{dl})$} \\
\hline$<100$ & $297(88.7)$ & $194(65.3)$ & $103(34.7)$ \\
\hline$\geq 100$ & $38(11.3)$ & $33(86.8)$ & $5(13.2)$ \\
\hline
\end{tabular}


Table 2 Distribution of dyslipidemia by behavioral and lifestyle characteristics of employees of Awash wine factory in Addis Ababa, Ethiopia, $2021(n=335)$

\begin{tabular}{|c|c|c|c|}
\hline \multirow[t]{3}{*}{ Variables } & \multirow{3}{*}{$\begin{array}{l}\text { Total } \\
\text { N (\%) }\end{array}$} & \multicolumn{2}{|c|}{ Dyslipidemia } \\
\hline & & Yes & No \\
\hline & & n (\%) & n (\%) \\
\hline \multicolumn{4}{|c|}{ Current tobacco smoking } \\
\hline No & $312(93.1)$ & $209(67.0)$ & $103(33.0)$ \\
\hline Yes & $23(6.3)$ & $18(78.3)$ & $5(21.7)$ \\
\hline \multicolumn{4}{|c|}{ Current alcohol consumption } \\
\hline No & $86(25.7)$ & $47(54.7)$ & $39(45.3)$ \\
\hline Yes & $249(74.3)$ & $180(72.3)$ & $69(27.7)$ \\
\hline \multicolumn{4}{|l|}{ Current chat chewing } \\
\hline No & $288(86.0)$ & $193(67.0)$ & $95(33.0)$ \\
\hline Yes & $47(14.0)$ & $34(72.3)$ & $13(27.7)$ \\
\hline \multicolumn{4}{|c|}{ Vegetables eating frequency } \\
\hline$\geq 2$ days per week & $116(34.6)$ & $66(56.9)$ & $50(43.1)$ \\
\hline$<2$ days per week & $219(65.4)$ & $161(73.5)$ & $58(26.5)$ \\
\hline \multicolumn{4}{|c|}{ Fruits eating frequency } \\
\hline$\geq 2$ days per week & $60(17.9)$ & $35(58.3)$ & $25(41.7)$ \\
\hline$<2$ days per week & $275(82.1)$ & $192(69.8)$ & $83(30.2)$ \\
\hline \multicolumn{4}{|l|}{ Eggs eating frequency } \\
\hline$\geq 2$ days per week & $111(33.1)$ & $68(61.3)$ & $43(38.7)$ \\
\hline$<2$ days per week & $224(66.9)$ & $159(71.0)$ & $65(29.0)$ \\
\hline \multicolumn{4}{|c|}{ Vigorous-intensity physical activities } \\
\hline No & $296(88.4)$ & $206(69.6)$ & $90(30.4)$ \\
\hline Yes & $39(11.6)$ & $21(53.8)$ & $18(46.2)$ \\
\hline \multicolumn{4}{|c|}{ Regular walking for 30 min or more } \\
\hline No & $228(68.1)$ & $71(66.4)$ & $72(31.6)$ \\
\hline Yes & $107(31.9)$ & $156(68.4)$ & $36(33.6)$ \\
\hline \multicolumn{4}{|c|}{ Sitting duration per day (hours) } \\
\hline$<4$ & $183(54.6)$ & $114(62.3)$ & $69(37.7)$ \\
\hline$\geq 4$ & $152(45.4)$ & $113(74.3)$ & $39(25.7)$ \\
\hline \multicolumn{4}{|c|}{ Sleeping duration per day (hours) } \\
\hline$<6$ & 39 (11.6) & $25(64.1)$ & $14(35.9)$ \\
\hline$\geq 6$ & $296(88.4)$ & $202(68.2)$ & $94(31.8)$ \\
\hline
\end{tabular}

was higher among women (68.9\%) and elevated triglyceride level was higher among men (38.5\%) (Fig. 1).

\section{Factors associated with dyslipidemia}

Eleven independent variables that were significant at $p$-value $<0.05$ in the bivariable logistic regression analysis were entered into the multivariable logistic regression analysis to identify factors independently associated with dyslipidemia. According to the multivariable logistic regression analysis, older age, alcohol consumption, eating vegetables for two days or less per week, sitting four hours or more per day, and raised waist circumference had a statistically significant association with the prevalence of dyslipidemia. Participants aged $30-39$ years and 40 years and older were about two times $(\mathrm{AOR}=2.51 ; 95 \%$ CI $1.16-5.44, p=0.019)$ and six times $(\mathrm{AOR}=6.45 ; 95 \%$ CI 2.01-20.71, $p=0.002)$ more likely to develop dyslipidemia, respectively, as compared to those less than 30 years of age. Current alcohol consumers were about three times more likely to develop dyslipidemia (AOR =3.37; 95\% CI 1.70-6.66, $p<0.001$ ) as compared to those who don't consume alcohol. Participants who eat vegetables fewer than two days per week had a $2.9(\mathrm{AOR}=2.89 ; 95 \% \mathrm{CI} 1.54-5.43, p=0.001)$ times higher risk of developing dyslipidemia when compared to their counterparts. Similarly, participants who sit four hours or more per day were about two times more likely to develop dyslipidemia (AOR $=1.96$; 95\% CI 1.03-3.74, $p=0.041$ ) as compared to those with a sitting duration of fewer than four hours per day. The odds of dyslipidemia among participants with raised waist circumference was $4.6(\mathrm{AOR}=4.56 ; 95 \% \mathrm{CI} 2.07-10.08, p<0.001)$ times higher as compared to those with a normal waist circumference (Table 3).

\section{Discussion}

Dyslipidemia with its increasing prevalence is a common public health problem in developing countries and a major contributing factor to the development of cardiovascular diseases. This study was conducted to assess factors associated with dyslipidemia and its prevalence among Awash wine factory employees in Addis Ababa, Ethiopia. Our findings from this study revealed a high prevalence of dyslipidemia, 67.8\% (95\% CI 62.5-72.7\%) among employees of Awash wine factory in Addis Ababa. Reduced HDL-C was the most prevalent type of dyslipidemia, $50.7 \%$, followed by elevated triglycerides, $33.4 \%$. The prevalence of elevated total cholesterol and elevated LDL-C was $25.4 \%$ and $21.5 \%$, respectively. Participants with older age and raised waist circumference had a higher risk of developing dyslipidemia. Moreover, consuming alcohol, eating vegetables for two days or less per week, and sitting four hours or more per day were significantly associated with dyslipidemia.

The overall prevalence of dyslipidemia reported in this study is consistent with the findings reported in Mekelle, 66.7\% [18], and Durame, southern Ethiopia, 65.6\% [15]. However, the prevalence is higher than the findings reported in Africa, 29.7\% [4], Eastern Ethiopia, 34.8\% [6], China, 43.3\% [1], India, 50.7\% [22], Iran, 51.8\% [23], Sao Paulo, 59.74\% [24], Nigeria, 60\% [25], and Togo, 60.3\% [5]. The reason for the high prevalence in this study might be attributed to differences in sample sizes, study setting, study population, socio-economic status, and lifestyle of the study participants [23]. In contrast, the prevalence is lower than the findings reported in Iran, 83.4\% [26], and 


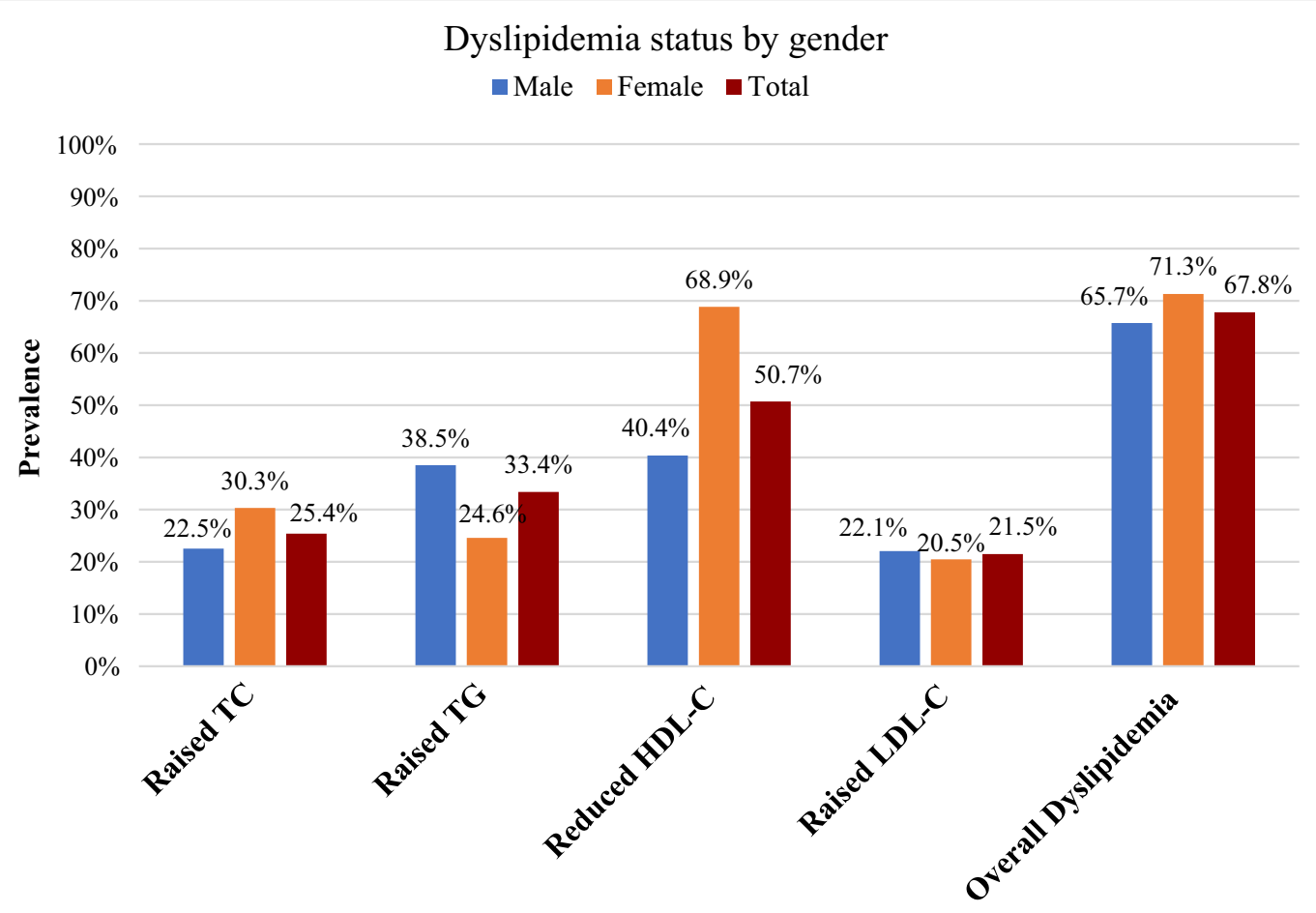

Types of dyslipidemia

Fig. 1 Prevalence of dyslipidemia by gender among employees of Awash wine factory in Addis Ababa, Ethiopia, $2021(n=335)$

Hawassa, southern Ethiopia, 90.8\% [16]. The presence of co-morbidity might be the main reason for the higher prevalence in the study from Southern Ethiopia [20], as it was conducted among hypertensive patients.

The most prevalent type of dyslipidemia was reduced HDL-C, 50.7\% followed by elevated triglycerides, 33.4\%, which is comparable with the findings from Ethiopia, [9], Iran [23], and Venezuela [27]. The prevalence of reduced HDL-C in this study, $50.7 \%$ is higher than the findings reported in Togo, 16.4\% [5], Mekelle, 16.5\% [18], China, 20.8\% [1], and Durame, southern Ethiopia, 41.9\% [15]. Whereas, it is lower than the findings from India, $62 \%$ [22], and Ethiopia, 68.7\% [9]. These variations might be due to differences in cut-off values, distribution of risk factors, study setting, and socio-economic status of the participants.

The prevalence of elevated triglyceride in this study, $33.4 \%$ is higher than the findings reported in Nigeria, 5\% [25], Africa, 17\% [4], Ethiopia, 21\% [9], China, 22.5\% [1], and India, 27\% [22]. However, higher prevalence were reported in studies conducted in Venezuela, 39.7\% [27], Mekelle, 40.2\% [18], Saudi Arabia, 44\% [7], and Hawassa, southern Ethiopia, 62.2\% [16].

The prevalence of elevated total cholesterol in this study, $25.4 \%$ is almost consistent with the study findings reported in Venezuela, 22.2\% [27], Nigeria, 23\% [25],
Durame, southern Ethiopia, 23.7\% [15], and Africa, 25.5\% [4]. Whereas, higher prevalence of elevated total cholesterol was reported in studies conducted in different parts of Ethiopia; Mekelle, 30.8\% [18], Eastern Ethiopia, 33.7\%, Hawassa, southern Ethiopia, 38.7\% [16], and Togo, 64\% [5]. In contrast, lower prevalence were reported in studies from Ethiopia, 5.2\% [9], India, 15.3\% [22], and Zambia, $15.8 \%$ [28].

The prevalence of elevated LDL-C in this study, $21.5 \%$ is comparable with the study findings reported in Hawassa, southern Ethiopia, 21\% [16], Africa, 21.4\% [4], India, 23\% [22], and Venezuela, 23.3\% [27]. However, it is higher than the study findings reported in China, $8.3 \%$ [1], Ethiopia, 14.1\% [9], and India, 15.8\% [29]. On the other hand, a higher prevalence of elevated LDL-C was found in Nigeria, 51\%; similarly, it was reported to be the highest prevalent type of dyslipidemia in different parts of Ethiopia [6, 15, 18].

The prevalence of dyslipidemia in this study was significantly higher in those aged $30-39$ years and $\geq 40$ years, $68.5 \%$ and $87.4 \%$, respectively, which is similar to the results reported in studies in Ethiopia, Iran, and China $[1,6,15,18,23]$. Gender was not significantly associated with dyslipidemia in this study. However, findings in many previous studies reported that women had a significantly higher prevalence of dyslipidemia $[15-17,26,30]$. 
Table 3 Multivariable logistic regression analysis of factors associated with dyslipidemia among employees of Awash wine factory in Addis Ababa, Ethiopia, $2021(n=335)$

\begin{tabular}{|c|c|c|c|c|c|c|}
\hline \multirow[t]{3}{*}{ Variables } & \multicolumn{2}{|c|}{ Dyslipidemia } & \multirow{3}{*}{ COR $(95 \% \mathrm{Cl})$} & \multirow{3}{*}{$p$-value } & \multirow[t]{3}{*}{ AOR $(95 \% \mathrm{Cl})$} & \multirow[t]{3}{*}{$p$-value } \\
\hline & Yes & No & & & & \\
\hline & n (\%) & n (\%) & & & & \\
\hline \multicolumn{7}{|l|}{ Age (years) } \\
\hline$<30$ & $30(38.5)$ & $48(61.5)$ & 1 & & 1 & \\
\hline $30-39$ & $100(68.5)$ & $46(31.5)$ & $3.48(1.96-6.18)$ & $<0.001$ & $2.51(1.16-5.44)$ & 0.019 \\
\hline$\geq 40$ & $97(87.4)$ & $14(12.6)$ & 11.09 (5.38-22.83) & $<0.001$ & $6.45(2.01-20.71)$ & 0.002 \\
\hline \multicolumn{7}{|l|}{ Marital status } \\
\hline Unmarried $^{\mathrm{a}}$ & $85(56.7)$ & 65 (43.3) & 1 & & 1 & \\
\hline Married & $142(76.8)$ & $43(23.2)$ & $2.52(1.58-4.04)$ & $<0.001$ & $1.43(0.73-2.82)$ & 0.300 \\
\hline \multicolumn{7}{|l|}{ Total service years } \\
\hline$<5$ & $70(53.0)$ & $62(47.0)$ & 1 & & 1 & \\
\hline $5-9$ & $58(66.7)$ & $29(33.3)$ & $1.77(1.01-3.11)$ & 0.046 & $1.39(0.65-2.99)$ & 0.395 \\
\hline$\geq 10$ & $99(85.3)$ & $17(14.7)$ & $5.16(2.78-9.57)$ & $<0.001$ & $1.83(0.71-4.70)$ & 0.208 \\
\hline \multicolumn{7}{|c|}{ Monthly income (ETB) } \\
\hline$<5000$ & $41(53.9)$ & $35(46.1)$ & 1 & & 1 & \\
\hline 5000-9999 & $124(72.5)$ & $47(27.5)$ & $2.52(1.28-3.95)$ & 0.005 & $1.83(0.88-3.80)$ & 0.104 \\
\hline$\geq 10,000$ & $62(70.5)$ & $26(29.5)$ & $2.04(1.07-3.87)$ & 0.030 & $1.11(0.45-2.72)$ & 0.827 \\
\hline \multicolumn{7}{|c|}{ Current alcohol consumption } \\
\hline No & $47(54.7)$ & $39(45.3)$ & 1 & & 1 & \\
\hline Yes & $180(72.3)$ & $69(27.7)$ & $2.17(1.30-3.59)$ & 0.003 & $3.37(1.70-6.66)$ & $<0.001$ \\
\hline \multicolumn{7}{|c|}{ Vegetables eating frequency } \\
\hline$\geq 2$ days per week & $66(56.9)$ & $50(43.1)$ & 1 & & 1 & \\
\hline$<2$ days per week & $161(73.5)$ & $58(26.5)$ & $2.10(1.31-3.38)$ & 0.002 & $2.89(1.54-5.43)$ & 0.001 \\
\hline \multicolumn{7}{|c|}{ Sitting duration per day (hours) } \\
\hline$<4$ & $121(63.7)$ & $69(36.3)$ & 1 & & 1 & \\
\hline$\geq 4$ & $106(73.1)$ & $39(26.9)$ & $1.75(1.09-2.81)$ & 0.019 & $1.96(1.03-3.74)$ & 0.041 \\
\hline \multicolumn{7}{|c|}{ Waist circumference $(\mathrm{cm})$ (Male/Female) } \\
\hline$<94 / 80$ & $97(52.7)$ & $87(47.3)$ & 1 & & 1 & \\
\hline$\geq 94 / 80$ & $130(86.1)$ & $21(13.9)$ & $5.97(3.46-10.29)$ & $<0.001$ & $4.56(2.07-10.08)$ & $<0.001$ \\
\hline \multicolumn{7}{|c|}{ Body Mass Index $\left(\mathrm{kg} / \mathrm{m}^{2}\right)$} \\
\hline$<18.5$ & $2(40.0)$ & $3(60.0)$ & 1 & & 1 & \\
\hline $18.5-24.9$ & $118(57.3)$ & $88(42.7)$ & $2.01(0.33-12.29)$ & 0.449 & $1.12(0.13-9.61)$ & 0.919 \\
\hline $25-29.9$ & $80(85.1)$ & $14(14.9)$ & $8.57(1.31-56.01)$ & 0.025 & $1.64(0.17-16.12)$ & 0.673 \\
\hline$\geq 30$ & $27(90.0)$ & $3(10.0)$ & $13.50(1.57-115.93)$ & 0.018 & $2.58(0.19-33.51)$ & 0.468 \\
\hline \multicolumn{7}{|l|}{ Blood pressure } \\
\hline Normal $^{b}$ & $156(61.9)$ & $96(38.1)$ & 1 & & 1 & \\
\hline Raised $^{c}$ & $71(85.5)$ & $12(14.5)$ & $3.64(1.88-7.06)$ & $<0.001$ & $0.56(0.21-1.47)$ & 0.240 \\
\hline \multicolumn{7}{|c|}{ Fasting blood glucose (mg/dl) } \\
\hline$<100$ & $194(65.3)$ & $103(34.7)$ & 1 & & 1 & \\
\hline$\geq 100$ & $33(86.8)$ & $5(13.2)$ & $3.50(1.33-9.25)$ & 0.011 & $2.76(0.83-9.21)$ & 0.098 \\
\hline
\end{tabular}

COR, Crude Odds Ratio; AOR, Adjusted Odds Ratio; Cl, Confidence Interval

a Single, divorced, separated, widowed

${ }^{b}$ Blood pressure $<130 / 85 \mathrm{mmHg}$

c Blood pressure $\geq 130 / 85 \mathrm{mmHg}$ 
Whereas, contradictory findings were reported in China and Saudi Arabia [1,7]. The observed variations might be due to differences in gender composition, as in this study a relatively lower percentage of female participants were included. Additional reasons could be the diverse socioeconomic status, culture, and lifestyle of the participants which could result in different dietary habits.

Alcohol does modulate several components of the lipogenic pathway; for instance, it decreases the primary enzyme that regulates lipogenesis resulting in higher levels of plasma lipids [31]. Similarly, several studies have reported that alcohol consumption is positively associated with dyslipidemia [1,10-12, 32], which is consistent with the results of this study which revealed that alcohol consumption is significantly associated with dyslipidemia, mainly with reduced HDL-C and elevated triglycerides. This could be explained by working in an alcoholic beverage factory might increase the access to alcoholic beverages to the employees and the tendency of excessive alcohol consumption.

Similar to a previous study report in Eastern Ethiopia [6], less eating of vegetables is significantly associated with dyslipidemia in this study. The prevalence was higher among those who ate vegetables two days or less per week. Cigarette smoking was not significantly associated with dyslipidemia in this study, which is consistent with the findings reported in previous studies $[1,6,26]$ and contrary to the finding reported in Saudi Arabia [7]. This variation might be due to differences in sample size and frequency of smokers among the participants.

In this study longer sitting duration was also significantly associated with dyslipidemia. Those who sat four hours or more per day had a higher risk of developing dyslipidemia. A comparable finding was found in India which reported a sedentary lifestyle, which could be described by longer sitting and lying down, was significantly associated with dyslipidemia [29]. This could be explained by longer sitting duration means fewer calories are being burned, which might lead to storage of calories in the form of lipids [33].

Raised waist circumference was also significantly associated with dyslipidemia in this study, which is consistent with the findings reported in various previous studies $[1$, $24,26,29,34,35]$. This could be explained by as waist circumference increases energy might be stored in different forms of lipids. Contrary to the findings in many previous studies $[9,15,16,18,28]$, BMI was not significantly associated with dyslipidemia in this study. This could be explained by the evidence that BMI was pointed as a poor indicator of obesity or body fatness in previous studies [34].

Studies conducted in India [22] and Durame, southern Ethiopia [15] reported dyslipidemia is significantly associated with hypertension. Other studies from Eastern Ethiopia and Saudi Arabia $[6,7]$ showed that elevated fasting blood sugar level was significantly associated with dyslipidemia. Whereas, this study reported a contradictory finding. This variation might be due to differences in study population and age composition. For instance, the study in Eastern Ethiopia was conducted solely in the female gender, the study in India includes only male participants above 30 years of age, and the study in Durame, southern Ethiopia was a hospital-based study. Besides, differences in socioeconomic status and lifestyle of the participants could also be additional reasons.

This study has several limitations. Firstly, as a crosssectional study, it may not show the causal relationship between dyslipidemia and the assessed factors. Secondly, as an institution-based study, it lacks the ability to generalize the findings to the general population as a whole. Finally, using a purposive selection of the study site could have affected the representativeness of the sample. Despite these limitations, the findings of this study could be a great input to future broader studies.

\section{Conclusions}

This study revealed a high prevalence of dyslipidemia among Awash wine factory employees in Addis Ababa. This finding indicates that dyslipidemia is a significant public health problem among the alcoholic beverage industrial working population of developing countries. Older age was the only non-modifiable risk factor for dyslipidemia in this study. Other modifiable factors such as; alcohol consumption, less eating of vegetables, longer sitting duration, and raised waist circumference were also the significant risk factors of dyslipidemia in this study. Periodic screening of high-risk groups for early detection and treatment is needed along with effective health promotion and education which encourages a healthy lifestyle. Furthermore, broader studies with different study designs are needed to assess the association of lipid derangements with alcohol consumption.

\footnotetext{
Abbreviations

AIDS: Acquired Immune Deficiency Syndrome; AOR: Adjusted odds ratio; BMI: Body Mass Index; BP: Blood pressure; CHD: Coronary heart disease; Cl: Confidence interval; COR: Crude odds ratio; CVD: Cardio vascular disease; DALYs: Disability adjusted life years; DBP: Diastolic blood pressure; DM: Diabetes mellitus; ETB: Ethiopian birr; HDL: High-density lipoprotein; HIV: Human immunodeficiency virus; IDF: International diabetic federation; IRB: Institution Review Board; LDL: Low-density lipoprotein; NCD: Non-communicable disease; NCEP-ATP: National Cholesterol Education Program-Adult Treatment Panel; OR: Odds ratio; SBP: Systolic blood pressure; SD: Standard deviation; SPSS: Statistical package for the social sciences; TC: Total cholesterol; TG: Triglyceride; WHO: World Health Organization.
}

\section{Acknowledgements}

We would like to express our gratitude to the Public Health Department of St. Paul's Hospital Millennium Medical College for this opportunity. We also thank 
Awash Wine S.C, the data collectors, and study participants for their cooperation during the data collection process.

\section{Authors' contributions}

Daniel Angassa conceived and designed the study; adopted data collection instrument and acquisition of data; analyzed the data and interpreted findings. Samrawit Solomon and Awol Seid critically reviewed the manuscript. All authors read and approved the final manuscript.

\section{Funding}

We have not received any financial support from any institution/government; hence, the operation of the research is solely financed by the handling fee received from the authors.

\section{Availability of data and materials}

The datasets used and/or analyzed during the current study are available from the corresponding author on reasonable request.

\section{Declarations}

\section{Ethics approval and consent to participate}

Ethical clearance was obtained from the Institution Review Board (IRB) of St. Paul's Hospital Millennium Medical College, and Addis Ababa Public Health Research and Emergency Management Directorate. Prior to data collection, written informed consent was obtained from all participants. Moreover, study participants with previously unknown abnormal findings such as hypertension were linked to the factory clinic for further clinical evaluation. Most importantly, since the study was conducted during the period of the COVID-19 pandemic, all preventive measures as advised by the $\mathrm{WHO}$ and the national guideline were adhered to every part of the study mainly during data collection.

\section{Consent for publication}

Not applicable.

\section{Competing interests}

The authors declare that they have no competing interests.

\section{Author details}

${ }^{1}$ Lideta Sub-City Health Office, Addis Ababa, Ethiopia. ${ }^{2}$ School of Public Health, St. Paul's Hospital Millennium Medical College, Addis Ababa, Ethiopia.

Received: 10 July 2021 Accepted: 17 January 2022

Published online: 30 January 2022

\section{References}

1. Opoku S, Gan Y, Fu W, Chen D, Addo-Yobo E, Trofimovitch D, et al. Prevalence and risk factors for dyslipidemia among adults in rural and urban China: findings from the China National Stroke Screening and prevention project (CNSSPP). BMC Public Health. 2019;19(1):1-15.

2. Murphy A, Palafox B, Walli-Attaei M, Powell-Jackson T, Rangarajan S, Alhabib KF, et al. The household economic burden of non-communicable diseases in 18 countries. BMJ Glob Health. 2020:5(2):1-13.

3. Damasceno A. Noncommunicable Disease. Heart of Africa: Clinical profile of an evolving burden of heart disease in Africa; 2016. p. 155-157.

4. Noubiap JJ, Bigna JJ, Nansseu JR, Nyaga UF, Balti EV, Echouffo-Tcheugui $J B$, et al. Prevalence of dyslipidaemia among adults in Africa: a systematic review and meta-analysis. Lancet Glob Health. 2018;6(9):e998-1007.

5. Bassokla Ditorguéna W, Essozimna Guy B, Yawo Apélété A, Soukouna Francis D, Borgatia A, Souleymane $P$, et al. Profile and prevalence of dyslipidemia in workplace in Togo. J Health Environ Res. 2019;5(2):50.

6. Sufa B, Abebe G, Cheneke W. Dyslipidemia and associated factors among women using hormonal contraceptives in Harar town, Eastern Ethiopia. BMC Res Notes. 2019;12(1):120.

7. Al-Kaabba AF, Al-Hamdan NA, El Tahir A, Abdalla AM, Saeed AA, Hamza MA. Prevalence and correlates of dyslipidemia among adults in Saudi Arabia: results from a National Survey. Open J Endocr Metab Dis. 2012:02(04):89-97.
8. Noncommunicable diseases [Internet]. [cited 2020 Jan 26]. Available from: https://www.who.int/news-room/fact-sheets/detail/noncommuni cable-diseases.

9. Gebreyes YF, Goshu DY, Geletew TK, Argefa TG, Zemedu TG, Lemu KA, et al. Prevalence of high bloodpressure, hyperglycemia, dyslipidemia, metabolic syndrome and their determinants in Ethiopia: evidences from the National NCDs STEPS Survey, 2015. PLoS One. 2018;13(5).

10. Bessembinders K, Wielders J, van de Wiel A. Severe hypertriglyceridemia influenced by alcohol (SHIBA). Alcohol Alcohol. 2011:46(2):113-6.

11. Capurso NA, Petrakis I. Dyslipidemia associated with heavy alcohol use. Am J Addict. 2016;25(3):188-90.

12. Minzer $S$, Losno RA, Casas $R$. The effect of alcohol on cardiovascular risk factors: is there new information? Nutrients. 2020;12(4):1-22.

13. Cesaro A, Gragnano F, Fimiani F, Moscarella E, Diana V, Pariggiano I, et al. Impact of PCSK9 inhibitors on the quality of life of patients at high cardiovascular risk. Eur J Prev Cardiol. 2020;27(5):556-8.

14. Gragnano F, Natale F, Fimiani F, Cesaro A, Sperlongano S, Crisci M, Calabrò P. Adherence to proprotein convertase subtilisin/kexin 9 inhibitors in high cardiovascular risk patients. J Cardiovasc Med. 2018;19(2):75-7.

15. Bekele S, Yohannes T, Mohammed EA. Dyslipidemia and associated factors among diabetic patients attending durame general hospital in southern nations, nationalities, and people's region. Diabetes Metab Syndr Obes Targets Ther. 2017;10:265-71.

16. Agete TH, Eshetu NG. Factors associated with atherogenic dyslipidemia among hypertensive patients at southern Ethiopia. Int J Med Med Sci. 2018;10(7):86-93.

17. Henock A, Techalew S, Kinfe L. Dyslipidemia among diabetic patients in Southern Ethiopia: cross-sectional study. J Diabetes Endocrinol. 2015;6(4):19-24.

18. Gebreegziabiher G, Belachew T, Mehari K, Tamiru D. Prevalence of dyslipidemia and associated risk factors among adult residents of Mekelle City, Northern Ethiopia. PLoS ONE. 2021;16(2):e0243103.

19. World Health Organization. WHO STEPS Instrument for Chronic Disease. 2009;12.

20. Cholesterol N, Program E. Understanding cholesterol levels. Postgrad Med. 2000;108(7):125-6.

21. Powell EE, Jonsson JR, Clouston AD. Metabolic factors and nonalcoholic fatty liver disease as co-factors in other liver diseases. Dig Dis. 2010;28(1):186-91.

22. Wankhade PS, Pedhambkar RB, Pagare RS, Pedhambkar BS. Prevalence and risk factors of dyslipidemia among male industrial workers in India. Int J Commun Med Public Heal. 2018:5(4):1458.

23. Mohammadbeigi A, Moshiri E, Mohammadsalehi N, Ansari H, Ahmadi A. Dyslipidemia prevalence in Iranian adult men: the impact of populationbased screening on the detection of undiagnosed patients. World J Mens Health. 2015;33(3):167.

24. Garcez MR, Pereira JL, de Mello FM, Marchioni DML, Fisberg RM. Prevalence of dyslipidemia according to the nutritional status in a representative sample of São Paulo. Arq Bras Cardiol. 2014;103(6):476-84.

25. Oguejiofor OC, Onwukwe CH, Odenigbo CU. Dyslipidemia in Nigeria: prevalence and pattern. Ann Afr Med. 2012:11(4):197-202.

26. Darroudi S, Saberi-Karimian M, Tayefi M, Arekhi S, Motamedzadeh Torghabeh A, Seyedzadeh Sani SMR, et al. Prevalence of combined and noncombined dyslipidemia in an Iranian population. J Clin Lab Anal. 2018;32(8):1-7.

27. González-Rivas JP, Nieto-Martínez R, Brajkovich I, Ugel E, Rísquez A. Prevalence of dyslipidemias in three regions in Venezuela: the VEMSOLS study results. Arq Bras Cardiol. 2018;110(1):30-5.

28. Muula AS, Rudatsikira E, Babaniyi O, Songolo P, Mulenga D, Siziya S. Factors associated with high cholesterol levels in Lusaka, Zambia: a community-based study. Med J Zambia. 2012;39(4):12-7.

29. Joshi SR, Anjana RM, Deepa M, Pradeepa R, Bhansali A, Dhandania VK, et al. Prevalence of dyslipidemia in urban and rural India: the ICMRINDIAB study. PLoS One. 2014:9(5).

30. Aslesh OP, Jayasree AK, Karunakaran U, Venugopalan AK, Divakaran B, Mayamol TR, et al. Prevalence of hypercholesterolaemia among adults aged over 30 years in a rural area of north Kerala, India: a cross-sectional study. WHO South-East Asia J Public Health. 2016:5(1):70-5.

31. Steiner JL, Lang CH. Alcohol, adipose tissue and lipid dysregulation. Biomolecules. 2017;7(1) 
32. Huang $\mathrm{S}$, Li J, Shearer GC, Lichtenstein AH, Zheng X, Wu Y, et al. Longitudinal study of alcohol consumption and HDL concentrations: a community-based study. Am J Clin Nutr. 2017;105(4):905-12.

33. Bellettiere J, Winkler EAH, Chastin SFM, Kerr J, Owen N, Dunstan DW, et al. Associations of sitting accumulation patterns with cardio-metabolic risk biomarkers in Australian adults. PLoS ONE. 2017;12(6):1-17.

34. Zaid M, Ameer F, Munir R, Rashid R, Farooq N, Hasnain S, et al. Anthropometric and metabolic indices in assessment of type and severity of dyslipidemia. J Physiol Anthropol. 2017;36(1):1-10.

35. Biadgo B, Abebe SM, Baynes HW, Yesuf M, Alemu A, Abebe M. Correlation between serum lipid profile with anthropometric and clinical variables in patients with type 2 diabetes mellitus. Ethiop J Health Sci. 2017;27(3):215-26.

\section{Publisher's Note}

Springer Nature remains neutral with regard to jurisdictional claims in published maps and institutional affiliations.

- fast, convenient online submission

- thorough peer review by experienced researchers in your field

- rapid publication on acceptance

- support for research data, including large and complex data types

- gold Open Access which fosters wider collaboration and increased citations

- maximum visibility for your research: over $100 \mathrm{M}$ website views per year

At BMC, research is always in progress.

Learn more biomedcentral.com/submissions 